\title{
Ação Microbiológica de Filme de Acetato com Óleos Essenciais em Queijo Coalho
}

Sarah Maria Frota Silva (III,I), Maria Do Socorro Rocha Bastos (I),

Camila Mota Martins (III,I), Karina Maria Olbrich dos Santos (II), Antonio Silvio do Egito Vasconcelos (II), Kirley Marques Canuto (I)

(I) Embrapa - Embrapa Agroindústria Tropical (R. Dra. Sara Mesquita, 2270 - Pici, Fortaleza CE, 60511-110), (II) Embrapa - Embrapa Caprinos e Ovinos (Fazenda Três Lagoas, Estrada Sobral/Groaíras, CEP: 62010-970, Sobral-CE), (III) UFC - Universidade Federal do Ceará (Av. da Universidade, 2853 - Benfica, Fortaleza - CE, CEP 60020-181)

\section{Resumo}

As embalagens biodegradáveis têm sido amplamente exploradas como alternativas para substituição das embalagens convencionais. Estudos vêm sendo direcionados visando não somente a proteção, mas também a interação com o produto. Em alimentos as embalagens ativas atuam como barreira a agentes externos, contribuindo com uma melhor qualidade do produto e prolongando a vida de prateleira. A incorporação de substâncias antimicrobianas em embalagens é uma estratégia para solucionar o problema da contaminação microbiana em alimentos. Dentre as substâncias aplicadas, os óleos essenciais $(\mathrm{OE})$ têm recebido atenção especial por serem substâncias naturais. O presente estudo teve como objetivo avaliar a ação do filme de acetato de celulose adicionado com OE, de alfavaca cravo (Ocimum gratissumum) e capim limão (Cymbopogom citratus), na redução da contaminação microbiológica em queijo coalho bovino inoculados intencionalmente por Staphylococcus aureus. Na elaboração dos filmes utilizou-se acetato de celulose incorporados com uma concentração de 20 $\%(\mathrm{p} / \mathrm{v})$ de $\mathrm{OE}$ de alfavaca cravo e capim limão sendo a porcentagem deste calculada em relação ao peso do acetato de celulose e ainda uma solução filmogênica sem adição de $\mathrm{OE}$ (controle). Os queijos foram embalados com os filmes testes e armazenados em temperaturas de refrigeração e ambiente.

\footnotetext{
Referência:

Sarah Maria Frota Silva, Maria Do Socorro Rocha Bastos, Camila Mota Martins, Karina Maria Olbrich dos Santos, Antonio Silvio do Egito Vasconcelos, Kirley Marques Canuto. Ação Microbiológica de Filme de Acetato com Óleos Essenciais em Queijo Coalho. In: Anais do 12 Congresso Latinoamericano de Microbiologia e Higiene de Alimentos - MICROAL 2014 [= Blucher Food Science Proceedings, num.1, vol.1]. São Paulo: Editora Blucher, 2014.

DOI $10.5151 /$ foodsci-microal-283
} 
As análise microbiológicas foram realizadas em 3 tempos $(0,7,14$ dias). Os resultados da análise demonstraram que, o tratamento com $\mathrm{OE}$ de alfavaca reduziu $0,36 \mathrm{log}$ ufc/ml em 14 dias de armazenamento em temperatura de $8^{\circ} \mathrm{C}$, quando comparado ao controle. Já o tratamento com OE capim limão reduziu $0,42 \mathrm{log}$ ufc/ml em 7 dias de armazenamento em temperatura de $8^{\circ} \mathrm{C}$, quando comparado ao controle. Analisando-se os resultados do tratamento com $\mathrm{OE}$ de alfavaca nota-se que houve uma redução na população de Staphylococcus aureus em 7 dias além de apresentar maior estabilidade, mantendo a redução até o décimo quarto dia. Já o tratamento com OE de capim limão apresentou uma redução maior, porém com uma menor estabilidade permitindo o aumento de $0,5 \mathrm{log}$ ufc/ml entre o sétimo e o décimo quarto dia. Os filmes de acetato de celulose apresentaram uma discreta redução na contaminação por Staphylococcus aureus presentes nos queijos analisados. Esta redução foi mais acentuada no tratamento com $\mathrm{OE}$ de capim limão à temperatura de $8^{\circ} \mathrm{C}$, durante sete dias.

Palavras-Chave: Microbiológica, Óleo Essencial, Queijo, Filme, Acetato Agência de Fomento: Embrapa Agroindústria Tropical 